\title{
Hacia una nueva lógica del populismo: de la ruptura de las instituciones a la institucionalidad populista
}

\author{
Towards a new populist logic: From the breakdown \\ of institutions to a groundbreaking institutionality
}

MARÍA LUCIANA CADAHIA (Pontificia Universidad Javeriana), VALERIA CORONEL (FLACSOEcuador), JULIO GUANCHE (FLACSO-Ecuador) y SOLEDAD STOESSEL (UNLP-CONICET)

Artículo recibido: 28 de agosto 2018

Solicitud de revisión: 18 de diciembre 2018

Artículo aceptado: 25 de enero de 2019

Cadahia, María Luciana, Coronel, Valeria, Guanche, Julio y Stoessel, Soledad (2020). Hacia una nueva lógica del populismo: de la ruptura de las instituciones a la institucionalidad populista. Recerca. Revista de Pensament i Análisi, 25(1), pp. 25-46.

\section{Resumen}

En este artículo estudiaremos el vínculo entre las instituciones y el populismo mediante una experiencia concreta: la asignación universal por hijo (AUH) en Argentina. Para ello, vamos a dividir el artículo en tres partes. Primero, desarrollaremos un tipo de abordaje metodológico específico: el procedimiento coyuntural recogido por Mouffe para pensar el actual momento populista. Segundo, explicitaremos el debate teórico alrededor del vínculo entre instituciones y populismo y las dificultades que existen para pensar esta relación. Tercero, partiremos del caso concreto de la AUH, con objeto de mostrar sus tres momentos constitutivos: el surgimiento de la demanda popular, su apropiación y tramitación por parte del Gobierno y la transformación de la demanda en un derecho. Finalmente, señalaremos, a partir del caso estudiado, cómo la conflictividad rupturista de la institucionalidad populista puede ayudarnos a pensar, transnacionalmente, una lógica alternativa al neoliberalismo.

Palabras claves: populismo, instituciones, conflicto, AUH, democracia.

Abstract

This article aims to study the relationship between institutional policies and populism analyzing the Universal Assignment for Child (AUH) in Argentina. To achieve this objective we will divide the paper in three sections. Firstly, we will think the populist moment in this particular setting as a method of interpretation. Secondly, we will follow 
the theoretical debates about institutions and populism explaining the difficulty to think this relationship. Third, from the concrete case of AUH, in order to show the constitutive moments: the emergence of popular demand, its appropriation and processing by the government and the transformation of demand into a right. Finally, we will show how the rupturist conflict of populist institutionalism helps us conceive a transnational alternative to global neoliberalism.

Key Words: populism, institution, conflict, AUH, democracy.

\section{INTRODUCCIÓN: PENSAR EL POPULISMO DESDE LA COYUNTURA}

El término populismo ha vuelto a entrar en la escena del campo político e, incluso, ha llegado a afirmarse que nuestra época vive un momento verdaderamente populista (Mouffe, 2018; Villacañas, 2015). Tanto las experiencias de gobierno de este signo en varios países latinoamericanos, como la irrupción de propuestas populistas en Europa y Estados Unidos, nos permiten formular esta apreciación. Así, el populismo deja de pensarse, de manera exclusiva, como la lógica propia de sociedades periféricas y comienza a ser concebido como una experiencia política que organiza el sentido de nuestra coyuntura (Errejón, 2018; Stavrakakis, 2014, Villacañas, 2015; Fernández Liria, 2016). Esta nueva coyuntura populista implica, por tanto, un desafío en el campo del pensamiento social, ya que se modifican los contornos desde los cuales se ha teorizado sobre el populismo, y exige nuevas matrices explicativas que acompañen las transformaciones epocales que tienen lugar. Entre los diferentes desafíos que exige la reaparición de este término, hay uno que merece toda nuestra atención, a saber: ¿es posible pensar una institucionalidad populista? Sobre todo, si tenemos en cuenta que las principales críticas al populismo se han concentrado en postular el carácter profundamente antinstitucional y, por ende, antiliberal, de estos procesos. En ese sentido, el presente texto se propone desarmar este prejuicio antinstitucionalista sobre los gobiernos populistas y tratar de comprender si es posible hablar de una institucionalidad populista. Para llevar a cabo este objetivo general, vamos a dividir el artículo de la siguiente manera: primero, haremos una reconstrucción teórica que ayude a entender los problemas para pensar este vínculo y qué cambio de enfoque es necesario realizar; luego, mostraremos en qué sentido la coyuntura exige pensar el vínculo entre instituciones y populismo $\mathrm{y}$, finalmente, estudiaremos un caso paradigmático, el derecho a la asignación universal por hijo en Argentina, que nos permita pen- 
sar, desde un caso concreto, el vínculo entre populismo e instituciones. Así, desde este estudio de caso, podremos analizar el surgimiento de una demanda popular y su posterior tramitación contenciosa en un derecho republicano. El abordaje empírico de este caso se realizará en base a tres dimensiones: en primer lugar, el levantamiento hemerográfico de tres periódicos de circulación nacional (La Nación, Perfil y Página 12); en segundo lugar, el análisis de la normativa y sus cambios, desde el decreto presidencial del 2009 hasta la aprobación de la ley en el $2015 \mathrm{y}$, en tercer lugar, el estudio de los debates legislativos y los discursos sobre las normativas.

\section{LA VERITÀ EFECTUALE DEL POPULISMO}

Lo primero que cabe definir es cómo vamos a considerar el término populismo y, para ello, es preciso indicar que resulta posible delimitar tres usos diferentes: uno mediático, otro sociológico-empírico y otro teórico-formal. El primero de ellos suele emplearse para aglutinar todas las experiencias políticas que no encajan con el modelo de democracia liberal de mercado e, incluso, para asignarle un sentido peyorativo al populismo. Tan es así que, en el año 2016, la Fundación del Español Urgente - promovida por la agencia EFE y BBVA- declaró que la palabra populismo era la palabra del año (Martín, 2016). Aunque el uso mediático le dio gran visibilidad y contribuyó a delimitar la coyuntura política en términos populistas, también es cierto que generó una serie de confusiones alrededor de su uso, que permea en el campo de la academia y obstaculiza los esfuerzos por comprender las diferentes evoluciones del populismo y la racionalidad que le es propia. En lo que se refiere a este uso, entonces, es necesario diferenciar la dimensión espontánea y peyorativa - otorgada por los medios de comunicación - de su actual fuerza coyuntural, que ayuda a pensar aspectos pocos explorados dentro de la tradición populista.

El uso sociológico-empírico se inicia con el estudio práctico de las experiencias políticas concretas que se se remontan a principios del siglo XX, tanto en los Estados Unidos como en la Unión Soviética, y en ambos casos aluden a un tipo de organización política que apunta a las formas de vida populares (Ionescu y Gellner, 1970). Para el caso latinoamericano, el término comienza a consolidarse en los sesenta, a través de los estudios de autores como Torcuato Di Tella (1965) o Germani (2003). Es sobre todo este último quien, en un registro funcionalista, lo va a retomar para referirse a formas de gobiernos populares que: $a$ ) rompen con los Estados oligárquicos y elitistas; $b$ ) construyen un 
tipo muy específico de modernidad y c) establecen un vínculo entre los sectores populares y el poder estatal (Germani, 2003). Cabría resaltar que la lectura de Germani apuntaba a dar un marco explicativo a la crisis de los Estados oligárquicos y al surgimiento de formas de empoderamiento nacionalespopulares, en oposición a las democracias liberales europeas. Aunque el enfoque funcionalista es abandonado del ámbito de las ciencias sociales, el populismo entrará cíclicamente en el debate latinoamericano, sobre todo con los denominados neopopulismos de los años noventa y los populismos del siglo XXI (Barros, 2014: 315-344).

A partir de los estudios sociológicos-empíricos, se ha priorizado la necesidad de definir el concepto de populismo en un sentido más riguroso, al punto de consolidarse un uso teórico-político que no dejó de adquirir complejidad hasta llegar al importante libro de Ernesto Laclau La razón populista, el cual posibilitó una formalización de los estudios en el campo de la teoría y la filosofía política. Pero esto ha llevado a una tensión entre lecturas sociológicodescriptivas y teórico-formales (Laclau, 2009). En lo que se refiere a estos usos, nos vamos a situar en el intersticio del uso descriptivo y del teórico en los términos de un «pensamiento dentro de la coyuntura», siguiendo la vieja tradición inaugurada por Maquiavelo (Maquiavelo, 1961), reactivada y ampliada por Althusser en los años setenta (Althusser, 2004) y recogida recientemente por Mouffe en su último libro For a Left Populism (Mouffe, 2018: 9-15). ${ }^{1}$ Recordemos que Maquiavelo inaugura esta forma de tratar los problemas políticos al decir que su modo de proceder atiende a la «verità effectuale de la cosa» (Maquiavelo, 1961: 55). Y esto apunta a dos cuestiones importantes: por un lado, a la necesidad de adentrarse en la cosa misma de lo político y, por otro, a tratar la cosa en su dimensión efectiva, concreta. Althusser va a recoger estos dos aspectos de Maquiavelo y los interpreta como un modo de proceder coyuntural donde «los elementos teóricos solo están centrados en el problema político concreto en la medida en que este tema político está, al mismo tiempo, centrado en la práctica política» (Althusser, 2004: 56). Se observa, así, un vínculo muy específico con el caso estudiado, puesto que no se asume una relación de exterioridad con el dato, sino que estos, entendidos como relaciones de fuerzas reales y circunstanciales, determinan desde dentro la inmanencia de la cosa misma que va a ser teorizada: 
no es entonces la simple incicación de sus elementos, la enumeración de las circunstancias diversas, sino su sistema contradictorio, que plantea el problema político y designa su solución histórica, haciendo de él, ipso facto, un objetivo político, una tarea práctica (Althusser, 2004: 56).

Por eso, Althusser se encargará de precisar que trabajar desde la coyuntura, lejos de sugerir el tratamiento de los problemas políticos en términos coyunturales - como intenta hacerse en su uso mediático-, consiste, más bien, en comprender que la coyuntura exige el planteamiento de un problema práctico en términos teóricos. Dicho de otra manera, más que reflexionar «sobre un conjunto de datos concretos» $»^{2}$ - como si estuvieran a la mano y ante nosotros-, se trata de «someterse al problema que produce e impone el caso» (Althusser, 2004: 56), puesto que:

las verdades teóricas producidas de este modo solo lo son bajo el aguijón de la coyuntura $y$, tan pronto como son producidas, quedan afectadas en su modalidad por su intervención en una coyuntura totalmente dominada por el problema político que ella plantea y por la práctica política que requiere alcanzar el objetivo que propone (Althusser, 2004: 57).

Así, la verdad teórica queda afectada por la coyuntura y su eficacia está condicionada por el problema político que ella plantea. Cabría señalar que Mouffe va a recoger este planteamiento que Althusser propone a partir de Maquiavelo y lo empleará para teorizar sobre el actual momento populista. En este sentido, ella insistirá en este carácter intervencionista de la teoría, al enfatizar la distinción entre teorizar «sobre la coyuntura» y hacerlo desde «dentro de la coyuntura» (Althusser, 2004: 56; Mouffe, 2018: 9). Si lo primero alude a un punto de vista externo a la cosa misma que la autora desestima, el segundo, en cambio, reinterpreta, en clave contemporánea, la necesidad maquiavelianade trabajar la veritá effectuale de la cosa misma del populismo. Aunque el tipo de enfoque propuesto por Mouffe se centra en la realidad europea, consideramos que puede hacerse extensivo a las experiencias populistas latinoamericanas del siglo XXI. Pero, para ello, se vuelve necesario deshacer una serie de prejuicios teóricos alrededor del carácter antinstitucional del populismo.

2 La cursiva es nuestra. 


\section{INSTITUCIONES Y POPULISMO: LA NECESIDAD DE UNA NUEVA MATRIZ EXPLICATIVA}

Los estudios clásicos que ofrecen herramientas para pensar la relación entre instituciones y populismo, asociados sobre todo a la vertiente sociológica, tienen el inconveniente de asumir un punto de vista peyorativo, pues parten de una serie de prejuicios alrededor de la dimensión fallida del populismo, a saber: reducen la dimensión institucional a su contienda electoral o al vínculo parlamento-partido, sin tomar en cuenta la posibilidad de pensar la institucionalidad como un proceso más amplio, integrando la acción colectiva, la movilización social y su articulación con el Estado.

Ahora bien, estos presupuestos peyorativos condicionan los hallazgos que puedan hacerse y orientan una lectura negativa sobre el papel que el populismo le otorga a las instituciones (Germani, 2003; Zanatta, 2014). Al concebirse el populismo como una respuesta deficiente de los países periféricos, se lo asocia con una forma de construcción política que vendría a debilitar la dimensión institucional de la democracia y a ponerla al servicio de fines particulares. Van a ser sobre todo los estudios de carácter teórico-formal los que comenzarán a deshacer el nudo de prejuicios asociados al populismo, al mostrar su dimensión democratizadora (Canovan, 1981; Arditi, 2004) e, incluso, sus posibilidades emancipadoras (Laclau, 2009; Laclau y Mouffe, 2004). Sin embargo, estas teorizaciones vincularon el papel democratizador del populismo con la dimensión conflictual y rupturista, poniendo el acento en la capacidad organizativa (o articuladora) de la movilización social, arraigada por fuera de las instituciones. Más aún, la teorización propuesta por Laclau apuntó a la dimensión rupturista del populismo en los términos de una forma de articulación política destinada a crear una ruptura con las instituciones, propiciando una especie de equivalencia entre los de arriba y las instituciones (lógica diferencial) y los de abajo y el populismo (lógica de equivalencia) (Laclau, 2009: 107108).

Por tanto, nos encontramos en una disyuntiva entre los estudios dedicados a pensar las experiencias de gobierno de los populismos en términos antidemocráticos y las reflexiones democratizadoras del populismo en una vertiente antinstitucionalista. Alrededor de este problema encontramos algunos trabajos, como los de Panizza (2008), Aboy Carlés (2005, 2010) y Barros (2006), centrados en pensar los desplazamientos lógicos necesarios para hacer factible, desde la teoría laclausiana, la dimensión institucional del populismo. Pero si buscamos adentrarnos en el enfoque propuesto más arriba - pensar 
desde dentro de la coyuntura y asumir la necesidad que impone el caso-, se hace prioritario adoptar como punto de partida las circunstancias concretas desde donde se entreteje la posibilidad misma de una institucionalidad populista, esto es, pensar desde las prácticas mismas de los gobiernos populistas del siglo XXI. Es decir, sumergirse en un determinado campo de experiencia de gobiernos populistas que nos ayuden a comprender la lógica que organiza su institucionalidad. Sin desestimar la dimensión decisional que caracteriza este tipo de gobiernos, consideramos que también ha surgido un tipo de lógica institucional muy poco explorada hasta ahora en los estudios globales sobre el populismo, a saber: el momento de institución de derechos.

Este hecho nos permite pensar un vínculo entre las demandas populares y las instituciones que, aún pudiendo tener una dimensión decisional, escapa a la lógica de inmediatez. El estudio de este momento de instauración de derechos puede ayudar a hacer inteligible una forma de mediación entre los liderazgos políticos y las demandas populares que tome como objeto de indagación la dimensión institucional en su aspecto práctico, a la vez que nos obliga a replantearnos una serie de supuestos alrededor de la movilización social y de las instituciones. En el primer caso, se ha concebido la movilización social desde su capacidad para articularse alrededor de una insatisfacción y configurarla en la forma de una demanda popular. ${ }^{3}$ Los estudios sobre movimientos sociales han puesto el acento en cómo se positiviza un vínculo social (la exigencia) a partir de una negatividad (el incumplimiento por parte del Estado). Pero, si se trata de un gobierno populista que se apropia de la demanda y la introduce a través del conflicto en las instituciones hasta convertirla en un derecho, ¿estaríamos hablando simplemente de una lógica diferencial en términos laclausianos? ¿O se trata de otro tipo de mediación que aún no ha sido trabajada con el rigor que exige el caso? Responder a estas preguntas implica problematizar la creencia de que las instituciones deberían estar asociadas con la idea de consenso, con la ausencia de conflictos o con una mera lógica procedimental conducida por expertos sin intereses políticos. ¿Acaso la lógica práctica del populismo no saca a relucir la dimensión decisional, conflictual y contenciosa inherente a toda práctica institucional?

Si queremos deshacer los prejuicios sobre el populismo no es suficiente con enunciar la posibilidad teórica de hacerlo compatible con las instituciones, sino que hace falta adentrarse en las prácticas concretas que hagan inteli-

Hay estudios críticos sobre el concepto de demanda en Laclau (Barros, 2006). Nosotros no entraremos en ese debate, ya que nuestro interés está en el vínculo entre demanda e instituciones. 
gible esta posibilidad institucionalista. Se trata, entonces, de pensar cómo se establece el vínculo entre lo instituyente y lo instituido al momento de ampliar los derechos, lo cual implica estudiar en profundidad las conflictividades inherentes al proceso instituyente y a los discursos que convierten las demandas en un derecho. Al escoger el caso paradigmático de la asignación universal por hijo (AUH) en Argentina, resulta posible estudiar todo el proceso. Es decir, revisar desde la construcción de una demanda popular (lo instituyente) hasta su consolidación en un derecho social (lo instituido), teniendo en cuenta los distintos tipos de conflictividades alrededor de esta transformación. Si bien nos vamos a centrar en un solo país, y en un caso específico, lo cual limita nuestras pretensiones, consideramos que nos ayudará a entender una lógica de funcionamiento para, en otras oportunidades, compararla con otras experiencias populistas y delimitar unas coordenadas comunes a esta lógica transnacional. Los debates alrededor de la AUH nos permitirán pensar: 1) el vínculo entre la construcción de una demanda popular y los liderazgos políticos; 2) la dimensión conflictiva de los procesos de institucionalización de una demanda popular y 3) su materialización normativa (el tránsito de una demanda social por ingreso ciudadano plasmado en una consulta popular, luego transformado en un decreto presidencial y, finalmente, en ley de Estado).

\section{EL SURGIMIENTO DE UNA DEMANDA POPULAR}

Durante la etapa que gobernó el kirchnerismo en Argentina (2003-2016) tuvieron lugar varios procesos sociopolíticos que derivaron en un diseño político-institucional. Entre los más importantes cabe señalar las diversas leyes en el campo de los derechos humanos (desde el 2003), la ley de Servicios Audiovisuales (2009), la ley de Matrimonio Igualitario (2011), la ley de Identidad de Género (2012) y la asignación universal por hijo (2015). Aunque vamos a centrarnos en la última de estas leyes, podríamos afirmar que todas ellas se caracterizan por responder a dos momentos: la construcción de una demanda colectiva desde abajo y la asimilación de esta demanda por parte del Gobierno para convertirla en ley. Es importante señalar que entre esos dos momentos es posible apreciar diferentes lógicas articulatorias. En algunos casos se trata de demandas que, siendo construidas desde abajo, simplemente son apropiadas desde arriba, como ha sido el caso de las leyes de derechos humanos relacionadas con la última dictadura cívico-militar. En otros casos, en cambio, existe un momento intermedio entre la demanda y la ley, a saber: la configuración de 
un debate público entre especialistas, políticos y organizaciones sociales. Este momento intermedio cumple un rol sumamente importante. Por un lado, contrarresta el tratamiento puramente mediático del proyecto de ley, al propiciar la construcción de una opinión pública fuera del cerco periodístico. Y, por otro, permite visibilizar las tensiones internas entre los que están a favor de la demanda, los que están en contra y los que ponen reparos o hacen críticas a la forma de su implementación.

En lo que se refiere a los antecedentes de la AUH, ya en la década de los cincuenta se había implementado un sistema de asignaciones familiares orientado a mejorar las condiciones sociales de los trabajadores formales que tuvieran a cargo familiares. El régimen de bienestar que se configuró se apoyó en la premisa de que la inclusión social, a través de la protección social y la garantía de derechos sociales, posibilitaba la incorporación de los hombres al mercado de trabajo. Durante las siguientes décadas el régimen de bienestar unificó distintos programas y asignaciones familiares que estaban disponibles. Pero el cambio de modelo económico, que comenzó con las dictaduras cívicomilitares en los años setenta, supuso, por un lado, el abandono de las políticas de inclusión y protección social por parte del Estado y, por otro, la incorporación de recetas neoliberales (Bertranou, 2010). Este abandono por parte del Estado se tradujo en un crecimiento del desempleo y del trabajo informal, pero, a su vez, sentó las bases para la construcción de los movimientos sociales. Es decir, la articulación de sectores afectados que comenzaban a construir una serie de demandas para exigir derechos sociales. Así, se observa cómo diferentes organizaciones sociales empezaron a plantear, desde abajo, la necesidad de universalizar las asignaciones familiares vigentes desde los años cincuenta. Por otra parte, en medio del contexto de la crisis económica que comenzó a agudizarse a finales de la década de 1990, el Estado argentino se vio en la obligación de crear los programas de transferencias monetarias condicionadas (PTC). Entre ellos apareció el Plan Trabajar, que se postuló como un programa de emergencia social a raíz del aumento exponencial del desempleo. Consistía en un plan masivo de empleo público mediante el cual los beneficiarios debían ofrecer una contraprestación laboral en el área de la construcción y de la infraestructura comunitaria. Se estima que dicho plan alcanzó a cubrir a doscientas mil personas (Gasparini y Cruces, 2010). Sin embargo, precisamente por sus magros resultados para superar los índices de desempleo, este programa fue asimilado a los de transferencias monetarias (condicionadas) y no a una política pública laboral. La siguiente experiencia de política social con amplios alcances fue en el marco de la crisis del 2001, cuando se recrudecieron los índices 
de pobreza, indigencia y desempleo. Esta política se denominó Programa Jefes y Jefas de Hogar Desocupados (PJJHD) y se creó vía decreto presidencial (número 565/02) durante el gobierno del expresidente Duhalde. Fue planteado originalmente como un programa para «asegurar un derecho familiar de inclusión social» (Neffa, 2009: 289; Ministerio de Trabajo, Empleo y Seguridad Social, Resolución 312/o2). Y la particularidad de este plan es que incluyó algunas demandas populares realizadas por movimientos y organizaciones sociales, como la Central de Trabajadores de la Argentina (CTA). La Central creó el Frente Nacional contra la Pobreza (FRENAPO), el cual aglutinó a una variedad de organizaciones de defensa de los derechos humanos, organizaciones productivas, dirigentes políticos, legisladores, miembros de las iglesias, etc. (Rossi, 2014).

Paralelo a estas políticas puntuales por parte del Estado, entre finales de los años 1990 y comienzos del 2000, comenzó a instalarse en el espacio público la necesidad de instaurar un ingreso ciudadano universal. La figura del ingreso ciudadano para la niñez se colocó en el centro de la plataforma de reivindicaciones y es un antecedente muy importante para la asignación universal por hijo (Lo Vuolo 2009). En parte porque allí empieza a construirse la demanda popular, a través de organizaciones y movimientos sociales como la CTA y el FRENAPO (Vales, 2002). A la vez, este frente lanzó la iniciativa de realizar una consulta popular para la implementación de un seguro de empleo y formación para los jefes y jefas de familia desocupados, bajo la consigna de «Ningún hogar pobre en la Argentina» (Echaide, 2005; Vales, 2003). La consulta popular, no vinculante, fue inédita en la medida en que la sociedad argentina no estaba acostumbrada a emplear los mecanismos de democracia directa que se habían incorporado en la Constitución de 1994. Participaron más de tres millones de personas y el resultado fue mayoritariamente por el sí. La consulta otorgó una gran experiencia de acción colectiva y promovió una acumulación de fuerza social que se expresaría durante el nuevo ciclo político posneoliberal desde el 2003 (Echaide, 2005: 13).

\section{LA INSTITUCIONALIZACIÓN DE UNA DEMANDA POPULAR}

Lo primero que hace falta señalar es que la demanda popular de un ingreso ciudadano fue primeramente recogida por plataformas de distintos partidos políticos del arco opositor al gobierno de Cristina Fernández de Kichner (CFK). Entre quienes presentaron proyectos de ley en el Congreso se encuen- 
tran: Argentinos por una República de Iguales (ARI) en 1997, la Coalición Cívica y el Partido Socialista en el 2008, la Unión Cívica Radical y Proyecto Sur en el 2009. Sobre estos proyectos, Cristina Fernández de Kirchner mencionó en algunas intervenciones públicas que el problema de ellos consistía en que carecían de una propuesta sobre los recursos con los que podría ejecutarse. Uno de los diputados del oficialismo, Agustín Rossi, llegó a expresar que «obviamente, el debate va a tener que incluir la cuestión presupuestaria. Si la asignación sale tanta plata, ¿cómo se conseguirán los recursos?» (Piqué, 2009).

Ahora bien, pese a los reparos iniciales por parte de la expresidenta CFK, estos proyectos comenzaron a estudiarse en tres comisiones de la Cámara de Diputados: la Comisión de Familia, Mujer, Niñez y Adolescencia, la de Trabajo y la de Salud. Y, a partir de allí, comenzó una tensión entre los partidos políticos que habían liderado primeramente la demanda y la apropiación posterior por parte del oficialismo. En esa dirección, Victoria Donda, diputada del Movimiento Libres del Sur —afín al socialismo y distante del Gobierno«contó que dentro del bloque oficialista se dejó de lado el debate sobre "la focalización o universalidad" de la asignación, para finalmente abordarla como "una política de Estado"» (Jorquera, 2009), es decir, se abandonaba una de las exigencias que se habían realizado desde las organizaciones sociales: su carácter irrestrictamente universal. A lo que la diputada oficialista, Juliana Di Tu1lio, argumentó diciendo que «[1]a Presidenta nos pidió que fuera un proyecto sustentable y responsable» (Jorquera, 2009), dando a entender que debía asumirse de manera focalizada para tener en cuenta su alcance y viabilidad. El temor de hacer una propuesta focalizada era que, en palabras de Donda, «los planes focalizados facilitan el armado de redes clientelares que sirven para sostener poderes territoriales» (Jorquera, 2009). Esto es, se le reprochaba al Gobierno convertir la AUH en un instrumento para obtener poder territorial mediante mecanismos clientelares. El debate ejemplificaba, así, el carácter contencioso entre el oficialismo y la oposición, al momento de definir quién lideraría el proyecto y si se convertiría en una política de Estado o si lograría ser capitalizado como un logro de la oposición.

Ahora bien, pese a los distintos proyectos en curso, el Gobierno tomó la decisión de anunciar la creación de la asignación universal por hijo a través de un decreto presidencial. Algunos sostienen que hacerlo por decreto le permitió al Gobierno «despojar a sus opositores de una bandera que reclamaban como propia y concentrar todo el crédito en sus manos» (Zarazaga, 2014: 82). Pero eso sería desconocer que CFK reconoció en varios actos públicos que esta demanda provenía de distintos sectores (anuncio AUH, Decreto 1602/o9, 2009). 
Más aún, el primer considerando del decreto reconoce que «los más diversos sectores políticos y sociales han expresado su predisposición favorable a la adopción de políticas públicas que permitan mejorar la situación de los menores y adolescentes en situación de vulnerabilidad social» $\mathrm{y}$ «[q]ue existe consenso entre la comunidad y las instituciones sobre la urgencia en implementar medidas que permitan combatir la pobreza» (Decreto 1602/og). En lo que se refiere a la naturaleza de esta medida, se afirma que:

por sí no puede garantizar la salida de la pobreza de sus beneficiarios y no puede ubicarse allí toda la expectativa social, aunque resultará, confiamos, un paliativo importante. Queremos evitar entonces el riesgo de depositar la ilusión de que con una sola medida se puede terminar con la pobreza [...] No implica necesariamente el fin de la pobreza, pero inocultablemente ofrece una respuesta reparadora a una población que ha sido castigada por políticas económicas de corte neoliberal (Decreto 1602/o9).

Cabe resaltar que la implementación de este decreto recibió tanto críticas como elogios. En el caso de la CTA —uno de los organismos de base que había configurado la demanda durante los años 1990-, celebraba la iniciativa a través de su portavoz Hugo Yasky, al decir que «se trataba de "un avance trascendental" producto de "una lucha histórica" la asignación» (Perfil, 2009). En esa misma línea, uno de los dirigentes sindicales más importantes, y afín al Gobierno en ese momento, Hugo Moyano, llegó a tildarla como una medida «revolucionaria» (Perfil, 2009). A diferencia de las organizaciones de base, que veían con buenos ojos esa medida, los partidos políticos de la oposición manifestaron su rechazo. Se volvió a insistir sobre el carácter clientelar y la ausencia de universalidad. Lilita Carrió, diputada de la Coalición Cívica-ARI y una de las impulsoras del ingreso ciudadano a la niñez, llegó a manifestar que se trataba de una «universalidad mentirosa» y «"una trampa" porque se trataba de un "acuerdo" con el jefe de la CGT, Hugo Moyano, para que el camionero "tenga clientes también en los desocupados"» y añadió que «es perverso lo que hace la presidenta» (Perfil, 2009). En sintonía con este discurso, Adrián Pérez, diputado del mismo partido que Carrió, señaló que el «Congreso debe sancionar el ingreso ciudadano a la niñez que llegue a todos los menores de 18 años de la Argentina» porque «el programa del Ejecutivo no es universal y mantiene los planes focalizados para que sea el Estado el que determine quién puede y quién no puede recibir el beneficio» (Perfil, 2009). 
Y Patricia Bullrich, diputada de Unión por Todos, fue contundente al decir que este decreto «Continúa con el sistema clientelar del gobierno para coartar libertades políticas y sociales de los ciudadanos en situación de pobreza» (Perfil, 2009).

Es en este escenario conflictivo que la AUH trata de configurarse como una respuesta reparadora por parte del Estado, a la vez que se anuncia como un mecanismo institucional para revertir los daños de las políticas económicas durante el neoliberalismo. El oficialismo delimita dos visiones de Estado completamente diferentes e irreconciliables, y es desde este carácter contencioso que concibe la reparación social como una forma de construir derechos. Así, se visibiliza la dimensión política y contenciosa del decreto, puesto que explicita un conflicto social previo entre la economía neoliberal (los de arriba) y los sectores vulnerables de la población (los de abajo). A la vez que el nuevo rol del Estado consistiría en estar del lado de los oprimidos al interior de esa frontera antagónica. Dentro de esta narrativa expresada en el decreto, el Estado no vendría a anular el conflicto, sino a tomar una posición específica, mediante una política reparadora. Por tanto, no se trataría de una retórica meramente técnica que buscase simplemente otorgarle mayor eficacia institucional a un Estado, sino que trata de visibilizar su dimensión politizadora.

A pesar de ello, es necesario prestar una cuidadosa atención a las críticas por parte del arco político opositor, quienes denunciaban un vínculo clientelar entre los beneficiaros, los dirigentes populares y el Gobierno. A ese respecto, cabe resaltar que la implementación de la AUH estuvo liderada por la Administración Nacional de la Seguridad Social (ANSES), un organismo estatal encargado de gestionar las prestaciones de seguridad social (Decreto 1602/og). Este organismo tiene una amplia penetración territorial y un nivel de gestión pública relativamente sofisticado sin tener que pasar por el clientelismo territorial al que hacían referencia algunos diputados de la oposición. Por lo general, los programas de transferencia estaban regidos bajo la órbita del Ministerio de Desarrollo Social y de allí se derivaban a los intendentes, creando así un manejo clientelar con organizaciones sociales beneficiadas de dichos programas (Repetto y Díaz Langou, 2010). Para evitar este estigma clientelar, la ANSES elaboró un manual de operaciones donde se estipularon claramente los criterios con los que se definiría el universo de beneficiarios y logró sistematizar y centralizar de forma rápida y eficiente la información para la conformación del registro de beneficiarios. En este sentido, es importante señalar que la AUH reconfigura el entramado de vínculos sociopolíticos con las organizaciones y referentes territoriales en la medida en que no requiere de la participación de 
intermediarios políticos para su implementación y, sobre todo, fortalece el proceso institucional y no clientelar de acceso a este derecho.

\section{DEL BENEFICIO AL DERECHO INSTITUIDO}

Tras probarse el éxito de la AUH, ${ }^{4}$ el 15 de junio de 2015 Cristina Fernández de Kirchner anuncia la propuesta de convertirlo en una ley, con la finalidad de darle mayor espesor institucional y crear un mecanismo automático de revisión del monto - algo que hasta el momento estaba sujeto a decisión discrecional del ejecutivo-. En palabras de la expresidenta, constatamos que: «con esto vamos a lograr que la AUH no esté sujeta a que alguien quiera licuar el beneficio y que pase a ser un recuerdo con el paso del tiempo. Es un sistema que en serio funciona. Cuídenlo y manténganlo» (Lewkowicz, 2015).

Es importante señalar que, desde inicios del 2015, diversos sectores de la oposición ya venían expresando la necesidad de que la AUH se convirtiese en una ley. Referentes de la Unión Cívica Radical bregaban porque CFK decidiera dar curso a dicho debate antes de que finalizase su mandato presidencial. El senador Federico Martínez sostuvo que sería «un orgullo» votar a favor de dicho proyecto (La Nación, 22 de junio, 2015). Asimismo, referentes del PRO también se definían en esa línea. Gabriela Michetti, senadora nacional y candidata a vicepresidenta junto a la fórmula de Mauricio Macri, sostuvo que:

estamos totalmente de acuerdo en la continuidad y fortalecimiento de la Asignación Universal por Hijo [...] Creemos que hay que hacerlo por ley. La Presidenta ha decidido hacerlo por decreto, pero nosotros creemos que tiene que ser una ley del estado argentino y hay que extenderlo; es un derecho que tiene que ser universal, estamos totalmente convencidos (La Nación, 22 de junio, 2015).

Varios funcionarios del Gobierno, como el titular de la ANSES, habían contraargumentado alegando que el decreto de la AUH era considerado positivamente por todo el arco opositor y que revestía el mismo estatus jurídico que una ley gracias a que había sido ratificada por la comisión bicameral del Congreso y luego por el pleno de la Cámara de Diputados (La Nación, 22 de junio,

\footnotetext{
Para el año 2015, la AUH constituía una de las políticas de protección social más gravitantes de las últimas décadas en Argentina, ya que ha tenido una cobertura mayor en comparación a otros programas. Dicho valor ascendía a 837 pesos (64 dólares). Algunas estimaciones sostienen que para el año 2012 esta contribución correspondía al 30 \% de la canasta básica total de una familia tipo (Zarazaga, 2014). Para el año 2013, la AUH alcanzaba a tres millones y medio de nińos y nińas.
} 
2015). De todas formas, el proyecto de ley fue presentado primero en la Cámara de Senadores y luego en la Cámara de Diputados, y en ambos casos aprobada por amplia mayoría, lo cual pone en evidencia dos cosas: el adecuado diseño institucional y el éxito de su implementación mediante decreto.

En ese sentido, el oficialismo hizo énfasis en tres aspectos fundamentales: 1) el carácter conflictual de una sociedad que exige este tipo de medidas; 2) el hecho de que los jóvenes menores de 18 años en situación de pobreza son sujetos de derechos a los que el Estado debe responder y 3) el reconocimiento de que se trata de una demanda popular histórica y construida desde abajo. En esa dirección, el presidente de la Comisión de Presupuesto, Feletti, anunciaba que:

hemos venido a completar con este proyecto lo que fue la ley de movilidad previsional que hizo que trabajadores argentinos que se habían desenvuelto en un mercado informal - por empresarios inescrupulosos- pudieran acceder al haber provisional (La Nación, 16 de julio, 2015).

El discurso de Feletti, como en su momento el de CFK, hace explícita la situación de un mercado de trabajo informal que vulnera las condiciones de vida de los trabajadores. Así, la propuesta de ley no se muestra como una medida donde el Estado buscaría ayudar a los pobres, como si se tratara de una concesión, sino que la misma se asume como un paliativo que introduce el Estado ante sujetos de derecho que se ven afectados por un mercado laboral que los pone en esa situación de vulnerabilidad. Y a esto apunta claramente el discurso de apertura en la Cámara del Senado ofrecido por el senador Abal Medina, cuando dice que:

hoy tenemos registrados en la ANSES 12.746.0oo niños. El 98,4 por ciento de los chicos que tienen menos de 18 años y viven en la Argentina están en la base de la ANSES y, por lo tanto, son sujetos de derecho. [...] Y no solo estamos garantizando la universalidad de este beneficio, sino que también -creo yo que es aún más importante- estamos haciendo que este no pierda sentido en el tiempo, poniendo una movilidad garantizada por ley que ya no va a depender, simplemente, de la intencionalidad que tenga el gobierno de turno, sino que garantizamos que este derecho siga siendo y vaya permaneciendo en el tiempo de manera cada vez más justa y más clara (Cámara de Senadores de la Nación Argentina, 2015: 35).

Por otra parte, el diputado oficialista Depetri explicaba de qué manera:

la Asignación Universal por Hijo es la política de distribución del ingreso más importante y eficaz para los sectores populares de los últimos cincuenta años [...] es la decisión de 
colocar al Estado como garante de los sectores más necesitados. Fue una pelea de los movimientos sociales y de la Central de Trabajadores de la Argentina (CTA) en la década de los 9o, que como tantas otras reivindicaciones fueron cumplidas por el gobierno de Cristina Fernández de Kirchner (La Nación, 16 de julio, 2015).

Ahora bien, a pesar del acuerdo generalizado, varios diputados y senadores del arco opositor aprovecharon para hacer críticas de fondo. Federico Sturzenegger, del partido Propuesta Republicana (PRO), dijo que este «es un proyecto para acompañar» porque desde 1997 «hay 17 proyectos sobre asignaciones y provienen de todos los partidos» (La Nación, 16 de julio, 2015). De esta forma, Sturzenegger no estaba apoyando una propuesta del Gobierno kirchnerista, sino una demanda anterior que exigía una mayor cobertura (La Nación, 16 de julio, 2015). El legislador del Frente Renovador, Oscar Martínez llegó a afirmar que: «acompañamos el proyecto de actualización de los montos, pero ratificamos que el objetivo debe ser que sea verdaderamente universal y que el resultado de esta política sea que no haya ningún pibe pobre en la Argentina» (La Nación, 16 de julio, 2015). Desde la izquierda, Nicolás Del Cano ratificó su apoyo al proyecto, aunque advirtió que «hoy los trabajadores que apenas superan el costo de la canasta familiar tienen que pagar impuesto al salario» (La Nación, 16 de julio, 2015). Podríamos resumir diciendo que casi todos coincidían en: 1) resaltar el carácter restrictivo de la universalidad de la política; 2) desanclar la propuesta del kirchnerismo y 3) recordar que el Gobierno nacional, «una vez más», había hecho uso de mecanismos discrecionales y decisionistas para implementar la AUH. Si bien estas críticas son muy similares a las que otros diputados del arco opositor habían realizado previamente al decreto, en este debate apareció un nuevo elemento, puesto que algunos senadores y diputados fueron más allá y postularon la necesidad de reconceptualizar la política en términos republicanos. Es decir, se manifestó que la figura del pobre se alejaba del debate republicano y dejaba en un segundo plano la figura del ciudadano. Varios senadores, retomando la propuesta que había hecho años atrás Rubén Lo Vuolo respecto al ingreso ciudadano a la niñez, sostuvieron que se consideraba un derecho por ser ciudadano, no un beneficio por ser pobre:

como fuente de derecho, justamente, se establecía la niñez; no se cobraba por ser pobre sino por ser ciudadano. Este es un concepto filosóficamente distinto, significativo, que hace al concepto de universalidad, desechando la idea de cualquier tipo de política asistencial focalizada (Cámara de Senadores de la Nación Argentina, 2015: 46). 
Una senadora del Frente Progresista sostenía, en esta misma dirección, que:

no es lo mismo decir que una persona tiene derecho a una determinada cantidad de dinero porque es pobre o que tiene alguna característica distintiva fijada desde el poder que afirmar que tiene derecho porque se trata de un derecho reconocido a toda la población (Cámara de Senadores de la Nación Argentina, 2015: 46).

Cabe concluir que la posibilidad de convertir una demanda social, el ingreso ciudadano para la niñez, en un nuevo derecho aprobado por el órgano legislativo no estuvo exento de tensiones y desacuerdos irresolubles en lo que se refiere a los mecanismos de aplicación y también a las contradicciones internas entre su voluntad universalizadora y sus restricciones materiales. Se trató de una demanda construida desde abajo - a partir del recuerdo de un Estado que había perdido su rol social-, recogida por diferentes fuerzas políticas y materializada, primero por decreto y luego por ley, durante el mandato del Gobierno de Cristina Fernández de Kirchner.

\section{CONCLUSIONES}

A modo de conclusión, y siguiendo los discursos tanto oficiales como del arco opositor, la institucionalización de la demanda popular y la implementación de la ley no abandonó en ningún momento la dimensión conflictual que la constituye. La ley no vino a suprimir el conflicto y tampoco fue asumida como una medida procedimental carente de una dimensión política, sino que se instituyó como un derecho que permitió gestionar el conflicto a favor de las mayorías. Y también como una manera de fortalecer las capacidades de las partes del conflicto, a través del reconocimiento de sus derechos como insoslayables para el bien común y para la ciudadanización de los sujetos de las demandas. Así, se constata el inerradicable aspecto conflictivo de los procesos políticos populistas y la apelación a la dimensión antagónica como forma de reinstitucionalizar el orden social en clave democrática. Vimos que el proceso de implementación de la AUH puso en evidencia la dimensión polémica y litigante de estos procesos políticos. Durante las distintas intervenciones políticas los esquemas discursivos confrontativos, en que se identifican adversarios, fue una clave constructiva que permitió encuadrar las decisiones políticas. En esa dirección, los enfoques dominantes sobre el populismo, de corte politológico y liberal, que han colocado al populismo y a las instituciones en una relación de 
exterioridad y mutuamente excluyentes no nos ofrecen los marcos teóricos, analíticos e interpretativos para poder reflexionar sobre una coyuntura cuyas experiencias políticas a nivel transnacional parecen indicar lo contrario. Dicho de otra manera, al no disponer de marcos analíticos que nos permitan teorizar sobre la dimensión institucional del populismo, seguimos reproduciendo los prejuicios arraigados en el interior de la teoría. Esto ha conducido a la repetición de ideas manidas como la de que los populismos contemporáneos no estarían preocupados por construir/respetar las instituciones. Todo el proceso sociopolítico que dio como resultado la aprobación de la AUH y su posterior institucionalización en el 2015 permite dar cuenta, entonces, de que precisamente dicho nexo - populismo e instituciones - es el que debe ser estudiado en profundidad si queremos darle nuevos aires a la dimensión democrática del populismo como alternativa reparadora al neoliberalismo.

\section{BIBLIOGRAFÍA}

Aboy Carlés, Gerardo (2005). Populismo y democracia en la Argentina contemporánea. Entre el hegemonismo y la refundación. Estudios Sociales, 28(1), 125-149. doi: 10.14409/es.v28i1.2553.

Aboy Carlés, Gerardo (2010). Las dos caras de Jano: acerca de la compleja relación entre populismo e instituciones políticas. Pensamiento Plural, 7, 21-40.

Anuncio AUH, Decreto 1602/o9 (26 de noviembre, 2009). Más provincias con convenio por la Asignación Universal por Hijo de la ANSES. [Archivo de vídeo]. Recuperado de: https://www.youtube.com/watch?v=YxJqX52a6xM [Consultado el 12 de agosto de 2018].

Althusser, Lois (2004). Maquiavelo y nosotros. Madrid: Akal.

Arditi, Benjamin (2004). Populism as a Spectre of Democracy: A Response to Canovan. Political Studies, 52, 135-143. doi: 10.1111/j.14679248.2004.00468.x.

Barros, Sebastián (2006). Inclusión radical y conflicto en la constitución del pueblo populista. Confines, $2(3), 65-73$. 
Barros, Sebastián (2014). Momentums, demos y baremos: lo popular en los análisis del populismo latinoamericano. POSTData: Revista de Reflexión y Análisis Político, 19(2), 315-344.

Bertranou, Fabio (2010). Aportes para un piso de protección social en Argentina: el caso de las asignaciones familiares. Buenos Aires: Oficina de la OIT en Argentina. Proyecto ARG/o6/Mo1/FRA.

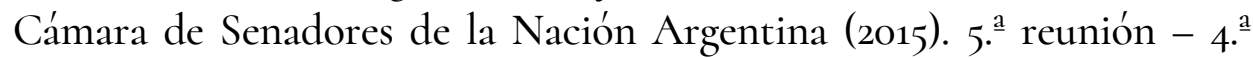
sesión ordinaria. 1 de julio de 2015. Versión taquigráfica.

Canovan, Margaret (1981). Populism. New York: Harcourt Brace Jovanovich.

Decreto 1602/o9. Asignación Universal por Hijo para Protección Social. Poder Ejecutivo Nacional. Recuperado de: http://www.trabajosocial.unlp.edu.ar/uploads/docs/decreto_1602_09_ _asignacion_universal_por_hijo_para_proteccion_social.pdf [Consultado el 13 de agosto de 2018].

Errejón, Íñigo (2018). España y Europa en la encrucijada entre teoría y praxis: para pensar los nuevos populismos. En Cadahia, Luciana, Coronel, Valeria y Ramírez Franklin (Eds.). A contracorriente: materiales para una teoría renovada del populismo (133-153). La Paz: Estado Plurinacional de Bolivia.

Fernández Liria, Carlos (2016). En defensa del populismo. Madrid: Catarata.

Gasparini, Leonardo y Cruces, Guillermo (2010). Las Asignaciones Universales por Hijo: Impacto, Discusión y Alternativas. Tesis de maestría. Universidad Nacional de La Plata.

Echaide, Javier (2005). Construcción de herramientas de resistencia contra el ALCA: El caso de la Consulta Popular de 2003 en Argentina. Informe final del concurso: ALCA, procesos de dominación y alternativas de integración regional. CLACSO.

Germani, Gino (2003). Autoritarismo, fascismo y populismo nacional. Buenos Aires: Temas.

Ionescu, Ghita y Gellner, Ernest (1970). Populismo: sus significados y características nacionales. Buenos Aires: Amorrortu. 
Jorquera, Miguel (27 de octubre, 2009). Un plan de 180 pesos por hijo. Recuperado de https://www.pagina12.com.ar/diario/elpais/1-1341822009-10-27.html [Consultado el 1o de diciembre de 2018].

La Nación (22 de junio, 2015). Gabriela Michetti: Estamos totalmente de acuerdo con la continuidad y el fortalecimiento de la AUH. Recuperado de: https:/www.lanacion.com.ar/1804025-gabriela-michettihay-que-fortalecer-la-asignacion-universal-por-hijo [Consultado el 10 de julio de 2018].

La Nación (16 de julio, 2015). Por Ley, la Asignación Universal por Hijo se actualizará dos veces al año. Recuperado de: https://www.lanacion.com.ar/1810747-1810747por-ley-la-asignacionuniversal-por-hijo-se-actualizara-dos-veces-al-ano [Consultado el 9 de agosto de 2018].

Laclau, Ernesto (2009). La razón populista. Buenos Aires: Fondo de Cultura Económica.

Laclau, Ernesto y Mouffe, Chantal (2004). Hegemonía y estrategia socialista. Buenos Aires: Fondo de Cultura Económica.

Lo Vuolo, Rubén (2009). La Asignación por Hijo. Serie Análisis de Coyuntura. Centro Interdisciplinario para el Estudio de Políticas Públicas, 21, 125 .

Lewkowicz, Javier (16 de junio, 2015). Esto es un logro, cuídenlo y manténgalo. Recuperado de: https:/www.pagina12.com.ar/diario/economia/2-275024-2015-o616.html [Consultado el 1o de agosto de 2018].

Maquiavelo, Nicolás (1961). Il Principe. Torino: Einaudi.

Martín, Alejandro (31 de diciembre, 2016). Y la palabra del año es... populismo. El País. Recuperado de: https://elpais.com/cultura/2016/12/3o/actualidad/1483100254_668323. html [Consultado el 1 de julio de 2018].

Mouffe, Chantal (2018). For a Left Populism. London: Verso.

Ministerio de Trabajo, Empelo y Seguridad Social. Resolución 312/o2, República Argentina. 
Neffa, Julio César (2009). El Plan Jefes y Jefas de Hogar Desocupados (PJyJHD). Análisis de sus características y objetivos. Fortalezas y debilidades. En Neffa, Julio César, De la Garza Toledo, Enrique, Muñiz Terra, Leticia y Antunes, Ricardo. Trabajo, empleo, calificaciones profesionales, relaciones de trabajo e identidades laborales. Buenos Aires: CLACSO-CAICYT.

Panizza, Francisco (2008). Fisuras entre populismo y democracia en América Latina. Stockholm Review of Latin American Studies, 3, 81-93.

Perfil (29 de octubre, 2009). La asignación «universal» por hijo que anunció Cristina Kirchner generó elogios y duras críticas. Recuperado de: https://www.perfil.com/noticias/politica/la-asignacionuniversal-por-hijo-que-anuncio-cristina-kirchner-genero-elogios-yduras-criticas-20091029-0039.phtml [Consultado el 10 de diciembre de 2018].

Piqué, Martín (16 de agosto, 2009). Un plan para que discuta el Congreso. Recuperado de: https://www.pagina12.com.ar/diario/elpais/1130075-2009-08-16.html [Consultado el 1o de agosto de 2018].

Repetto, Fabián y Díaz Langou, Gala (2010). Desafíos y enseñanzas de la Asignación Universal por Hijo para Protección Social a un año de su creación. Documento de Políticas Públicas / Recomendación N. 88. Buenos Aires: CIPPEC.

Rossi, Federico (2014). Conciliar agendas múltiples: la lucha de los sindicatos contra el neoliberalismo en Argentina. Revista CIDOB d'Afers Internacionals, 105, 165-189.

Stavrakakis, Yannis (2014). The Return of "the People": Populism and Anti-Populism in the Shadow of the European Crisis. Constellations, 21(4), 505-517. doi: 10.1111/1467-8675.12127.

Torcuato Di Tella (1965). Populismo y reforma en América Latina. Desarrollo Económico, 4(16), 391-425. doi: 10.2307/3465879.

Vales, Laura (12 de mayo, 2002). Pros y contras de un seguro. Recuperado de: https://www.pagina12.com.ar/diario/elpais/1-5040-2002-0512.html [Consultado el 3 de agosto de 2018]. 
Vales, Laura (5 de octubre, 2003). Una breve historia de los planes sociales. Recuperado de: https://www.pagina12.com.ar/diario/elpais/subnotas/26350-95962003-10-05.html [Consultado el 28 de julio de 2018].

Villacañas, José Luis (2015). Populismo. Madrid: La huerta grande.

Zanatta, Loris (2014). El populismo. Buenos Aires: Katz.

Zarazaga, Rodrigo (2014). Política y necesidad en Programas de Transferencias Condicionadas. La Asignación Universal por Hijo y el Programa de Inclusión Social con Trabajo «Argentina Trabaja». En Acuña, Carlos (Ed.). El estado en acción. Fortalezas y debilidades de las políticas sociales en la Argentina. Buenos Aires: Siglo XXI. 